\title{
Process Control: Higher Vocational College Practical Teaching of Ideological and Political Theory Analysis
}

\author{
Wang Xiaoqing \\ Yunnan Open University, kunming, China
}

\begin{abstract}
Higher vocational colleges and universities thought politics theory class practice teaching in the classroom practice teaching, campus practice teaching process, Should not only embody the characteristics of ideological and political theory course teaching in higher vocational colleges, And combined with the goal of higher vocational education, To practice teaching of ideological and political theory course in higher vocational colleges has brought many worth exploring, the study of space, Process of practice teaching of ideological and political theory teaching process control is the practice teaching of ideological and political theory teaching effect one of the useful means of ascension.
\end{abstract}

Index Terms - The teaching process control, Higher vocational education courses, The practice teaching

\section{过程控制：高职院校思想政治理论课实践教学分析}

\author{
王晓晴 \\ 云南开放大学, 云南, 昆明, 中国
}

\begin{abstract}
摘 要 高职院校思想政治理论课实践教学在课堂实践教学、校园实践教学过程中, 既要体现高职院校思想政治理论课教学的特 点, 又要结合高职院校人才培养目标要求, 从而给高职院校思想政治理论课实践教学带来了许多值得探讨、研究的空间, 对思想政治 理论课实践教学过程进行教学过程控制是思想政治理论课实践教学实现教学效果提升的有益手段之一。
\end{abstract}

关键词 教学过程控制, 高职思政课, 实践教学

\section{1. 实践教学过程控制的理论}

（一）实践教学过程控制来源于管理学控制理论,管理 学控制理论来源于维纳控制论。1948 年美国应用数学家 诺伯特·维纳出版《控制论一一关于在动物和机中控制和通 讯的科学》一书以后, 控制论的思想和方法渗透到了几乎 所有的自然科学和社会科学领域。在维纳的控制论中, 提 出来控制论四原则, 即普遍性原则、智能型原则、非决定 性原则、黑箱方法。

控制论引入管理学后, 控制成为管理的基本职能之一, 其基本原则是反映计划原则、面向未来原则、控制权责匹 配原则、行动原则、例外原则、控制关键点原则。按照控 制过程中控制措施的作用环节来划分的控制工作类型, 控 制工作可分为前馈控制、同期控制、反馈控制。而控制过
程可分为三个步骤: 衡量实际行动; 实际行动与标准进行 比较; 采取管理行动来纠正偏差或不足 ${ }^{[1]}$ 。

（二）根据维纳控制论及管理学控制理论, 我们可以 将实践教学过程控制定义为: 是监督、检查实践教学工作 是否按既定的教学计划、教学目标和教学方法进行, 发现 实践教学过程中的偏差, 分析原因, 进行纠正, 以保证教 学目标实现的过程。实践教学过程控制类型可分为教学前 馈控制、教学同期控制、教学反馈控制。教学控制过程根 据芮明杰的控制过程步骤的分类方法可分为确定实践教学 控制标准; 衡量实践教学的实际绩效; 对比分析实践教学 过程产生偏差原因; 对照实践教学标准纠正偏差。

\footnotetext{
[1]斯蒂芬.P.罗宾斯 玛丽.库尔特著 孙健敏等译.管理学 (第七版). 中国人民大学出版社, 2004 版
} 
(三) 实践教学过程控制类型分为教学前馈控制、教 学同期控制、教学反馈控制。教学前馈控制是在实践教学 实施之前, 对即将开始的实践教学进行前期准备, 即对会 出现什么样的情况进行预测准备工作, 也就是对事先设定 的实践教学目标是否能按计划完成, 实施过程中会出现什 么样的问题, 对出现的问题应采取什么样的措施解决等。

教学同期控制是实践教学进行过程中的控制, 主要是在实 践教学过程中, 任课教师对学生在实践教学自主参与过程 中的实时控制, 保证实践教学目标在教学过程中按计划完 成。教学反馈控制是实践教学结束后, 对照实践教学计划 和安排, 比对完成情况是否达到既定要求, 在学生中实践 教学效果如何, 并为下次实践教学的开展做好调整。

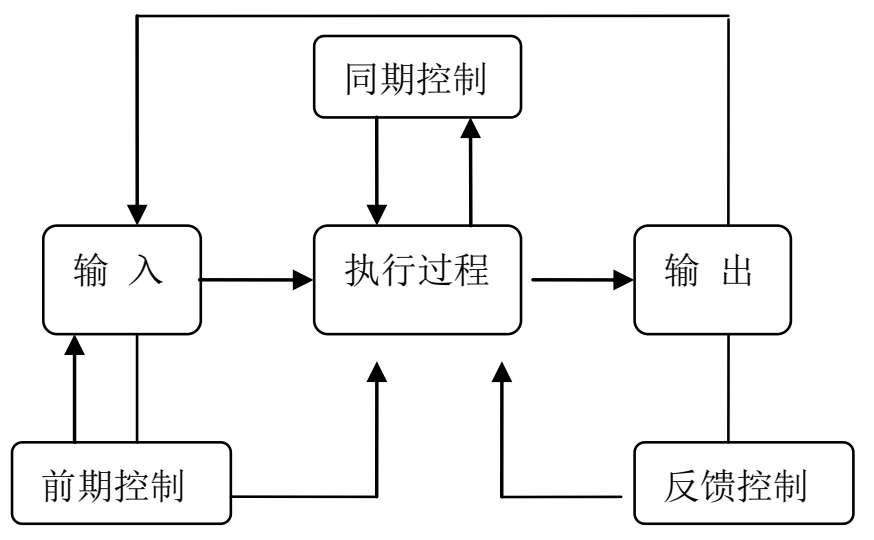

图 1.1 控制的类型

资料来源: 苪明杰: 《管理学---现代的观点》(第二 版）上海人民出版社 2005 年版

（四）实践教学控制过程根据芮明杰的控制过程步 骤的分类方法, 可分为四个步骤。第一是确定实践教学 控制标准。这一标准在实践教学中主要是教学计划的设 定, 通过任课教师和学生商议, 结合理论教学要求, 提 出实践教学计划或者是安排。第二是衡量实践教学的实 际绩效。主要是任课教师和学生在实践教学中的个人观 察与讨论, 各实践小组的作业报告等。第三是对比分析 实践教学过程产生偏差原因。从任课教师的角度查找教 学工作中出现问题的原因; 从学生角度查找实践学习过 程中自我的原因。第四是对照实践教学标准纠正偏差。 主要是对照实践教学计划或者是安排, 对计划或者是安 排是否需要改进, 对事先设置的实践教学计划或安排是 否需要调整。

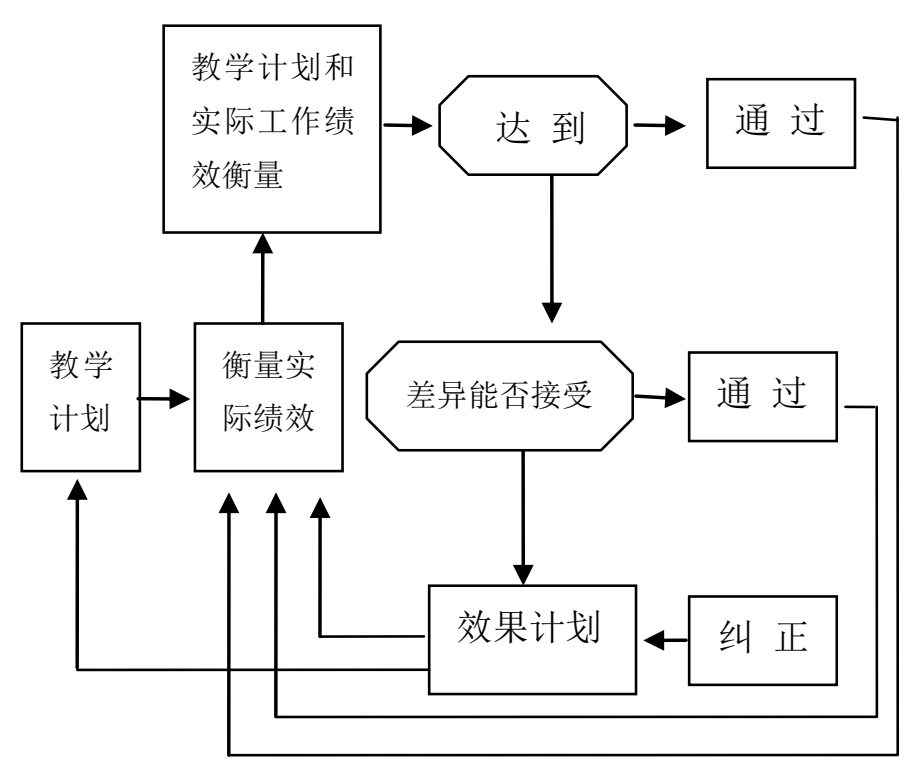

图 1.2 实践教学控制的过程

\section{2. 思想政治理论课实践教学过程控制分析}

\section{（一）课程班级情况}

笔者结合《思想道德修养与法律基础》理论课程, 在 电子商务班进行了一个学期实践教学的实践。本门课程 3 学分, 48 个课时, 周学时为三个课时, 结合电子商务班的 专业教学安排, 安排了一次课堂实践教学、一次校园实践 教学, 共用六个课时。按照《思想道德修养与法律基础》 教学大纲的要求, 结合电子商务专业人才培养模式的需要, 设定课堂实践教学主题为 “电子商务人员的职业操守”; 校 园实践教学主题为 “我的校园 我的大学生活”。

\section{(二) 实践教学过程。}

本文实践教学过程的实施以 “我的校园 我的大学生活” 为例。

1. 教学过程策划。成立实践教学课工作小组。为保障 实践教学课的实施效果, 本次课程主要由学习委员负责牵 头, 志愿者参加, 学生班干部协助, 专任教师全程参与, 组成实践教学课工作小组。课程内容的布置。由专任教师 将实践教学课的主题内容 “我的校园 我的大学生活” 布置 给工作小组, 主要是保障实践教学课主题不偏离教学要求, 突出中心, 便于实施。工作小组各司其职。按照教学过程, 工作小组进行工作分工, 各司其职, 主要是由学习委员整 体负责, 学生自由报名担任教学解说人, 并负责拟写解说 词, 制定校园参观路线。学生干部负责学习分组、参观秩 序维护等辅助工作。策划工作具体表格化。主要是将前期 策划工作, 要求工作小组以表格化的形式制作出来, 便于 
实施时一目了然, 让同学们迅速了解实践教学课要达到的 目标。

2. 教学过程实施。教学过程是学生学习的一个特殊的 认识过程, 是促进学生对学习认识深化的过程。在做好教 学过程策划前期准备的基础上, 对教学过程实施能否按照 策划安排顺利完成成为关键。按设计线路完成教学过程。 教学过程实施时, 专任教师尊重工作小组策划工作时作出 的线路安排, 协助工作小组严格按照设计线路, 分步骤逐 项实施。专任教师做好教学的资料补充工作。按照设计线 路, 在线路关键点, 专任教师在学生解说员讲解说明的基 础上, 进行提升讲解, 重点对学生解说员讲解不到位的地 方进行补充说明, 关键在于背景资料的补充完善。学生解 说员工作的完成。整个教学过程, 学生解说员的作用发挥 尤为关键, 发挥着整体安排、调度、指挥以及任务解说等 工作。学生解说员根据线路安排的关键点, 对校园重点景 观进行逐一解说, 让同学们知道校园景观设置命名的意义。 学生干部协助工作的完成。由于班级人数较多, 整个教学 过程以分小组的形式, 落实到学生干部和小组长, 由各小 组内的学生干部和小组长负责整个教学过程的有序完成。

学生教学过程笔记记录工作。由于教学过程是在校园内完 成, 无教材可用, 对参加学习的学生要求做好笔记记录工 作, 同时要求小组长对小组成员进行工作细化, 有同学负 责文字处理、有同学负责摄影、有同学负责关注问题等等。

3. 教学过程考核。本次实践教学过程考核采用结果考 核和过程考核相结合。结果考核是要求学生以实践教学主 题为内容, 按照小组完成学习感受的文章和小组 PPT 汇报 稿。过程考核依据着装及学习态度、小组 PPT 汇报时解说 人的语言表达及应变能力、实践课中小组队形及安全意识、 实践过程中小组成员对校园的环保意识、课后作业完成情 况等项成绩打分后汇总成实践课总评成绩。考核过程中, 评分由各小组选派一名监督员负责全程监督打分完成, 教 师只对教学过程教学指导。

(三) 实践教学效果。

1. 教学情况调查。实践教学实施完成后, 学生干部负 责组织对实践教学效果进行问卷调查。在任课教师的帮助 下, 负责效果调查的学生干部编制了 10 道问卷调查题, 主 要围绕实践教学计划的安排、实践教学过程、学生实践学 习效果等方面内容进行信息反馈。

由学生干部对学生进行问卷调查和统计。问卷回收率 $100 \%$ 。 $81 \%$ 的学生“实践课前对实践课相关资料做过收集”, $80 \%$ 的学生 “实践课前和同学做过与实践课相关的讨论”。 对实践课参与程度, $72 \%$ 的同学是 “积极参与”, $20 \%$ 的同
学是 “一般参与”。对 “实践课与专业相关程度”, $41 \%$ 的 同学认为 “紧密联系”, 59\%的同学认为 “有所关联”。63\% 的同学认为实践课效果 “很好”, $36 \%$ 的同学认为 “一般”, $2 \%$ 的同学认为 “无聊”。在对 “实践课这种形式对思想政 治理论课教学效果” 的了解方面, 70\%的同学认为 “很好”, $27 \%$ 的同学认为 “好”，3\%的同学认为 “一般”。

问卷调查集中的特点主要是: 同学认可, 思想一致, 效果明显, 目标达成。

2. 教学情况反馈。在学生对教学情况的反馈意见中, 有的同学认为 “......实践教学是思政课的有效延伸, 能够 引发我们关注现实的意识和热情, 实现知与行的统一。只 有让我们参与到实践中, 才能深入理解人生, 帮助我们找 到准确的人生定位和价值追求, 让我们刻骨铭心地认识到 正确的价值观在人生中的重要性。…..”有的同学认为 “......喜欢实践课, 特别是 (我的校园我的大学生活) 实 践课, 因为我们刚刚进入大学, 对校园的各种情况不是太 了解, 但是, 通过实践课, 我们对校园有了更多的了解, 使我们熟悉了我们的校园环境, 同时也改变了我们枯燥的 学习生活, 使我们感受到了学习的乐趣。......”有的同学 认为 “.....实践课更能激发我们的积极性, 让我们学到很 多知识, 也锻炼了我们同学之间的协作能、团结精神。......”

\section{3. 思想政治理论课实践教学过程控制的关键点}

通过《思想道德修养与法律基础》实践教学的实施, 在教学过程控制中, 有几个关键点需要控制。

（一）学生主体作用的发挥。思想政治理论课实践教 学的开展, 目的是为了提高学生思想政治素质和观察分析 社会现象的能力, 实现深化教育教学效果的目的, 因此学 生在实践教学过程中主体作用的发挥尤为重要。一是班级 学生干部作用的发挥。通过一定的授权, 给予参与实践教 学工作的学生干部一定的权限, 让学生干部把实践教学作 为自己的事情去思考, 去设计, 使实践教学主题更能贴近 学生, 同时又能使学生中共性需要解决的问题通过实践教 学达成一定的思想共识。二是学生分组组织作用的发挥。 实践教学分小组开展和全班统一开展比较效果明显, 小组 划分后, 对调动每个学生积极参与的推动力更具体, 同时 也便于负责的学生干部落实实践教学目标或计划的完成。

三是学生个体作用的发挥。由于实践教学给出的实践主题 是学生自己发挥主体作用设定的, 给学生自己的空间较大, 也就给学生在实践教学主题前提下联系自己的专业、爱好 做好实践教学提供了一定的条件。四是学生自己对实践教 学绩效进行考评。通过学生主体作用的发挥, 参加实践教 
学的学生都不同程度的提高了自己的能力。

(二) 实践教学计划的设置。实践教学计划或者是目 标的设置是保证实践教学过程顺利进行的前提。计划或者 是目标的设置首先要符合思想政治理论课理论教学和实践 教学要求, 设定时一定要让学生参与设计, 通过学生的参 与, 学生平时所想、所思, 自己不能解决的一些问题就显 现出来, 在设计过程的讨论、寻找中, 学生自己就能解决 一些认识上的问题, 通过教师的辅助引导式的讲评, 实现 教学效果的最大化。例如电子商务班同学对电子商务专业 的发展前景的困惑, 就通过课堂实践 “电子商务人员的职 业操守” 认识到了电子商务的职业背景、行业发展方向以 及目前国内电子商务的发展状态, 使学生们知道自己今后 的职业发展情况, 也使其知道在校期间应掌握什么样的理 论知识才能使自己适合社会的需要。因此, 在实践教学计 划的设置时要有针对性、可操作性。

(三) 任课教师教学过程的跟进。学生主体作用的 发挥并不等于就忽视任课教师的辅助作用, 整个实践教学 过程任课教师的全过程跟进是保证实践教学按质按量完成 的一个条件。任课教师在实践教学过程中就像 “一双眼睛” 注视着实践教学过程, 看看实践教学计划或者是目标设定 是否达到课程要求; 看看实践教学过程是否发生偏差, 以 及时提醒学生注意; 看看实践教学完成后, 出现差异的原 因在哪里, 是计划设置的问题还是实施过程中控制的问题, 是学生对计划理解不到位还是有新的情况出现等等。任课 教师跟进过程中要注意: 一是客观性原则, 使自己处于中 立的立场参与实践教学; 二是忘记身份原则, 就是忘记自 己是教师, 而是以旁观者身份, 看整个实践教学过程的推 进; 三是协调作用原则, 及时对实践教学过程中学生们控 制不到位的地方进行及时的协调, 保证实践教学按计划或 者是目标方向发展。

（四）教学过程的信息反馈。教学过程的信息反馈是
衡量实践教学效果的直接信息来源, 对反馈信息的及时分 析、梳理、鉴别、归类, 是下一次实践教学更高质量进行 的保证。教学过程的信息反馈可以采取多种形式进行, 如 实践教学总结会等形式。通过学生、任课教师对实践教学 过程的认识和理解, 看教学过程中做得好的地方和做得不 好的地方; 问卷调查形式。通过设计问卷, 采取不记名形 式了解学生对实践教学过程的开展情况的评价, 分析出现 不足的原因; 作业形式。通过做作业的形式, 了解学生在 实践教学过程中, 对教学计划或者是目标的理解是否加深, 对实践教学过程中自己认为好的地方或者是存在哪些不足 的地方, 需要进一步改进的措施和方法是什么等等。

\section{4. 结语}

思想政治理论课实践教学是思想政治理论课教学的重 要教学形式之一, 采取什么样的方法和手段开展好大学生 思想政治理论课实践教学, 是从事大学生思想政治理论课 教学工作者们一直在探讨的课题。本文希望做的探索, 是 将管理学控制理论与教育学相关理论相结合, 实现对思想 政治理论课实践教学的控制, 以保证思想政治理论课实践 教学的规范性、可操作性, 通过学科交叉研究, 寻找到对 大学生进行思想政治教育的有效途径和提高大学生思想政 治理论课教育教学效果的方法。

\section{参考文献}

[1] RuiMingiie. - modern point of view of management (second edition). Shanghai: Shanghai people's publishing house, 2005 edition. Simpson, et al, "Title of paper goes here if known," unpublished.

[2] Wiener Chen Buyi. That person - the use of cybernetics and society. Beijing: Peking University press, 2010

[3] Stephen p. Robbins Mary. Kurt the Sun Jianmin et al. Management (seventh edition). Beijing: renmin university of China publishing house, 2004 edition 